\title{
Substorms and polar cap convection: the 10 January 2004 interplanetary CME case
}

\author{
Y. Andalsvik ${ }^{1}$, P. E. Sandholt ${ }^{1}$, and C. J. Farrugia ${ }^{2}$ \\ ${ }^{1}$ Department of Physics, University of Oslo, Oslo, Norway \\ ${ }^{2}$ Space Science Center, University of New Hampshire, Durham, USA \\ Correspondence to: Y. Andalsvik (y.l.andalsvik@fys.uio.no)
}

Received: 19 October 2011 - Revised: 14 December 2011 - Accepted: 24 December 2011 - Published: 6 January 2012

\begin{abstract}
The expansion-contraction model of Dungey cell plasma convection has two different convection sources, i.e. reconnections at the magnetopause and in the magnetotail. The spatial-temporal structure of the nightside source is not yet well understood. In this study we shall identify temporal variations in the winter polar cap convection structure during substorm activity under steady interplanetary conditions. Substorm activity (electrojets and particle precipitations) is monitored by excellent ground-satellite DMSP F15 conjunctions in the dusk-premidnight sector. We take advantage of the wide latitudinal coverage of the IMAGE chain of ground magnetometers in Svalbard - Scandinavia - Russia for the purpose of monitoring magnetic deflections associated with polar cap convection and substorm electrojets. These are augmented by direct observations of polar cap convection derived from SuperDARN radars and cross-track ion drift observations during traversals of polar cap along the dusk-dawn meridian by spacecraft DMSP F13. The interval we study is characterized by moderate, stable forcing of the magnetosphere-ionosphere system $\left(E_{\mathrm{KL}}=4.0-4.5 \mathrm{mV} \mathrm{m}^{-1}\right.$; cross polar cap potential (CPCP), $\Phi($ Boyle $)=115 \mathrm{kV})$ during Earth passage of an interplanetary CME (ICME), choosing an 4-h interval where the magnetic field pointed continuously south-west $\left(B_{\mathrm{z}}<0 ; B_{\mathrm{y}}<\right.$ $0)$. The combination of continuous monitoring of ground magnetic deflections and the F13 cross-track ion drift observations in the polar cap allows us to infer the temporal CPCP structure on time scales less than the $\sim 10$ min duration of F13 polar cap transits. We arrived at the following estimates of the dayside and nightside contributions to the $\mathrm{CPCP}(\mathrm{CPCP}=\mathrm{CPCP} /$ day $+\mathrm{CPCP} /$ night $)$ under two intervals of substorm activity: $\mathrm{CPCP} /$ day $\sim 110 \mathrm{kV}$; $\mathrm{CPCP} /$ night $\sim 50 \mathrm{kV}$ ( $45 \%$ CPCP increase during substorms). The tem-
\end{abstract}

poral CPCP structure during one of the substorm cases resulted in a dawn-dusk convection asymmetry measured by DMSP F13 which is opposite to that expected from the prevailing negative $B_{\mathrm{y}}$ polarity of the ICME magnetic field, a clear indication of a nightside source.

Keywords. Ionosphere (Plasma convection) - Magnetospheric physics (Solar wind-magnetosphere interactions; Storms and substorms)

\section{Introduction}

The temporal structure in polar cap convection and the associated cross polar cap potential (CPCP) has been the subject of much study over the years. The presence of an underlying temporal structure was indicated by the large scatter appearing in plots of CPCP, as measured by low-altitude spacecraft, versus the geoeffective interplanetary electric field, $E_{\mathrm{KL}}$ (Kan and Lee, 1979) (see Cowley, 1984, his Fig. 3). An interpretation of this scatter in terms of the influence from the closure of open flux during substorm activity, i.e. satellite polar cap traversals under different substorm phases, was given by e.g. Lockwood and Cowley (1992). This is a natural consequence of the expansion-contraction model of polar cap convection (Siscoe and Huang, 1985; Cowley and Lockwood, 1992).

The same conclusion was reached on the basis of observations from SuperDARN radars by Shepherd et al. (2002). They found a highly variable CPCP for any given value of $E_{\mathrm{KL}}$. Thus they concluded that upstream parameters alone are not enough to describe the instantaneous CPCP value. Processes internal to the magnetosphere-ionosphere system must be included as well. 
In a case study Grocott et al. (2002) documented the excitation of new voltage during the substorm expansion phase. The total transpolar voltage typically increased by a factor of $2(100 \%)$ during the expansion phase. Milan et al. (2003) found that the polar cap contraction characteristic of the expansion phase continues throughout the recovery phase and can last as long as $100 \mathrm{~min}$ after substorm onset. Provan et al. (2005) observed by ground radars a $70 \%$ CPCP increase $(40 \mathrm{kV})$ during the $12 \mathrm{~min}$ interval following substorm onset.

In a recent study by Lockwood et al. (2009) it was found that the nightside source (magnetotail reconnection) of the $\mathrm{CPCP}$ dominates in the substorm expansion and recovery phases. The dayside source (MP reconnection) is the most important contributor to the CPCP in the growth phase only. An increase in the CPCP by a factor of 2 from growth to expansion phase was derived.

The MHD simulation study of Gordeev et al. (2011) shows a rapid response of the CPCP to substorm onset, but they find that the nightside contribution to the CPCP is generally less in magnitude than the dayside source. In their study, the CPCP typically increased by $25 \%$ after substorm onset.

From these examples we conclude that there is no consensus on the relative contributions to the total CPCP from CPCP/day and CPCP/night. According to Gordeev et al. (2011) "a direct quantitative evaluation of the efficiency of the nightside reconnection in contributing to the polar cap potential still awaits to be done." A reason for this might be that direct measurements of the CPCP temporal structure by ground radars are difficult to make because of limited coverage of these radars at the high polar cap latitudes. A widely used method to determine the CPCP is to integrate the $\boldsymbol{E}$-field component along the satellite track across the polar cap (Hairston et al., 1998). The temporal resolution of CPCP values derived from such cross-track ion drift observations during dawn-dusk traversals of the polar cap by low-altitude satellites is limited. As we shall see, the polar cap transit time of approx. $10 \mathrm{~min}$ may introduce deviations from the instantaneous CPCP value during intervals of transient convection sources. The presence of non-ideal satellite trajectories (deviations from dawn-dusk meridian) may also be a problem with this technique.

Indirect measurements in the form of ground magnetic deflections (the PC index) are widely used as an indicator of polar cap convection (Troshichev et al., 2011). Responses in polar cap ground magnetic deflections to the dayside and nightside convection sources has been distinguished by Kullen et al. (2010).

Our approach is to combine direct and indirect observations in order to derive a finer temporal structure in the CPCP. In this article we shall use this approach to focus on the magnetotail source of CPCP temporal structure, i.e. that related to substorm activity, by applying an appropriate combination of ground and satellite data as described next.
We shall combine continuous observations of (i) high latitude (Svalbard) magnetic deflections and (ii) cross-track ion drift observations during dusk-dawn passes by satellite DMSP F13. The continuous monitoring of the ground signature allows us to identify the temporal structure of polar cap convection on time scales shorter than the approx. 10 minlong traversal time of DMSP F13 across the polar cap. As noted above, the latter is a widely used technique to derive CPCP values.

The magnetotail source is monitored by its associated substorm electrojet activity. For the latter purpose we use ground-satellite DMSP F15 conjunctions in the duskpremidnight sector, and the AL auroral index.

The case we study occurred during an interval of ICME passage at Earth on 10 January 2004. We focus on a 4-h long interval when the stable ICME $B_{\mathrm{z}}$ component meaured by $\mathrm{ACE}$ lies within -5 to $-7 \mathrm{nT}$ after a rapid southward turning. The $B_{\mathrm{y}}$ component was negative throughout the whole interval. The corresponding geoeffective interplanetary electric field $\left(E_{\mathrm{KL}}\right.$ (Kan and Lee, 1979)) lies within $4.0-4.5 \mathrm{mV} \mathrm{m}^{-1}$.

The combination of the present data sets also allow us to document a non-traditional dawn-dusk convection asymmetry, as measured during a DMSP F13 polar cap transit, which may appear during intervals of substorm activity. Expectations on dawn-dusk convection asymmetries are based on the effect of IMF $B_{\mathrm{y}}$ on dayside convection (Jørgensen et al., 1972; Cowley et al., 1991). We hypothesize that the reversed asymmetry we observe is further evidence of a nightside contribution.

\section{Data description}

We shall study the evolution of plasma convection features and the associated CPCP during a 4-h-long interval of steady southwestly ICME magnetic field which contains two intervals of substorm activity. The interplanetary conditions associated with this interval of ICME passage, as recorded from ACE, are given in Fig. 1.

After describing the interplanetary data, we illustrate the observation geometry for this case study. Then we describe two ground-satellite conjunction studies which took place during the substorm intervals 15:50-16:40 UT and 17:4018:30 UT in more detail.

\subsection{Interplanetary conditions: ICME}

The interplanetary data from the MAG (Smith et al., 1998) and SWEPAM (McComas et al., 1998) instruments on ACE are shown (Fig. 1) for the interval 13:00-18:00 UT. From top to bottom, the panels show the proton density, bulk speed and temperature (in red: the expected temperature of the normal solar wind after Lopez, 1987), the $\alpha$ particle-to-proton number density ratio, the dynamic pressure, the GSM components of the magnetic field and the total field strength, 


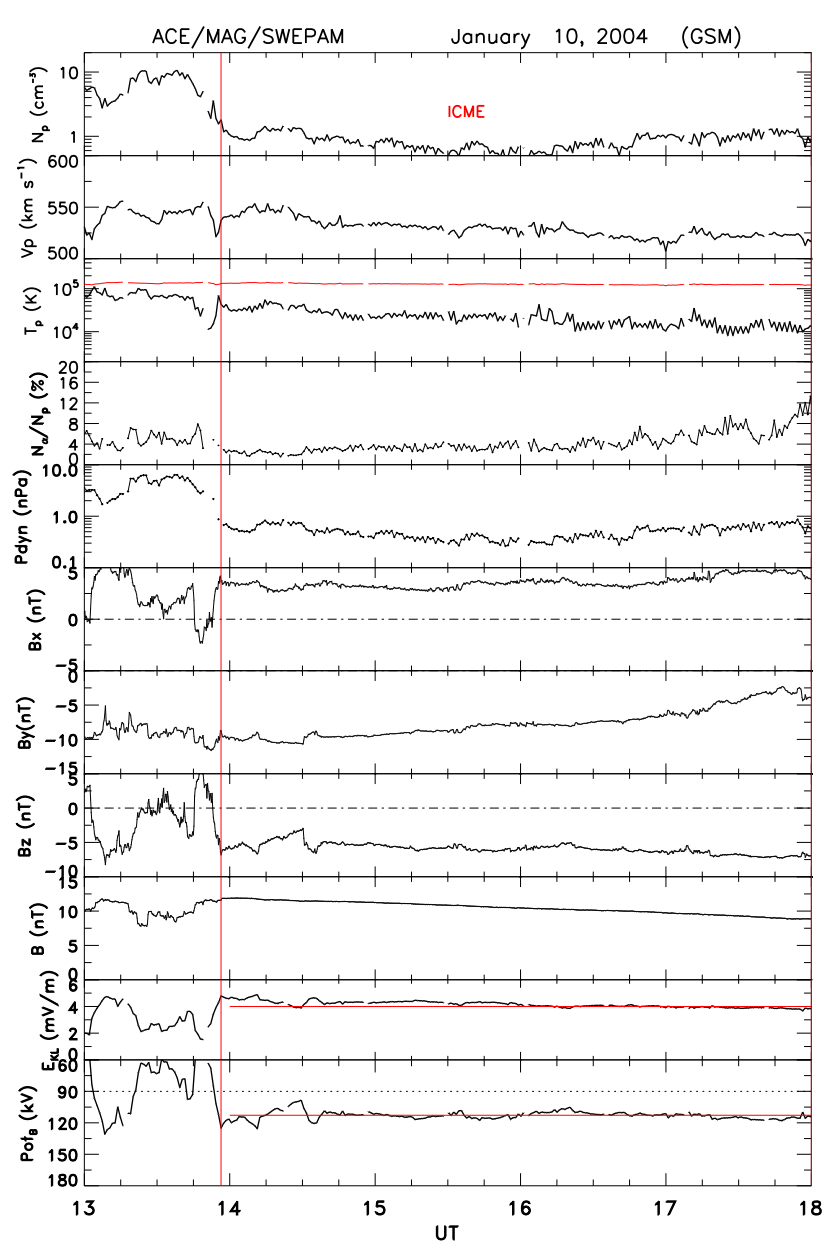

Fig. 1. Interplanetary parameters obtained from ACE during the interval 13:00-18:00 UT. Panels from top to bottom shows: (i) proton density, (ii) bulk speed, (iii) proton temperature, (iv) the alfa/proton density ratio), (v) dynamic pressure, (vi)-(ix) magnetic field components $B_{\mathrm{X}}, B_{\mathrm{y}}, B_{\mathrm{Z}}$, and the total field, (x) the geoeffective interplanetary electric field, $E_{\mathrm{KL}}$, and (xi) the Boyle potential. The ICME front boundary is marked by vertical guideline.

the interplanetary electic field in the formulation of Kan and Lee (1979) and the Boyle potential (see Boyle et al., 1997). The quantity $E_{\mathrm{KL}}$ is defined as $\left.V_{\mathrm{p}} \sqrt{(} B_{\mathrm{y}}^{2}+B_{\mathrm{z}}^{2}\right) \sin ^{2}$ (clock/2), where $\theta$ is the clock angle.

The interval we study, 14:00-18:00 UT, is characterized by an exceptionally slow and smooth rotation of the ICME magnetic field. The clock angle (not shown) increases slowly from $\sim 120^{\circ}$ to $160^{\circ}$. $B_{\mathrm{z}}$ lies within -5 to $-7 \mathrm{nT}$, while $B_{\mathrm{y}}$ is increasing from -10 to $-3 \mathrm{nT}$. The total field strength $\mathrm{B}$ decreases slowly from 12 to $8 \mathrm{nT}$. The bulk speed is decreasing from 550 to $520 \mathrm{~km} \mathrm{~s}^{-1}$ while the dynamic pressure lies below $1 \mathrm{nPa}$ throughout. The latter is lower than typical. The electric field, $E_{\mathrm{KL}}$, is very stable within $4-4.5 \mathrm{mV} \mathrm{m}^{-1}$. This is slightly smaller than values needed to saturate the CPCP (e.g. Muhlbachler et al., 2005, and references therein), so that a linear response of the CPCP to interplanetary driving is ex-

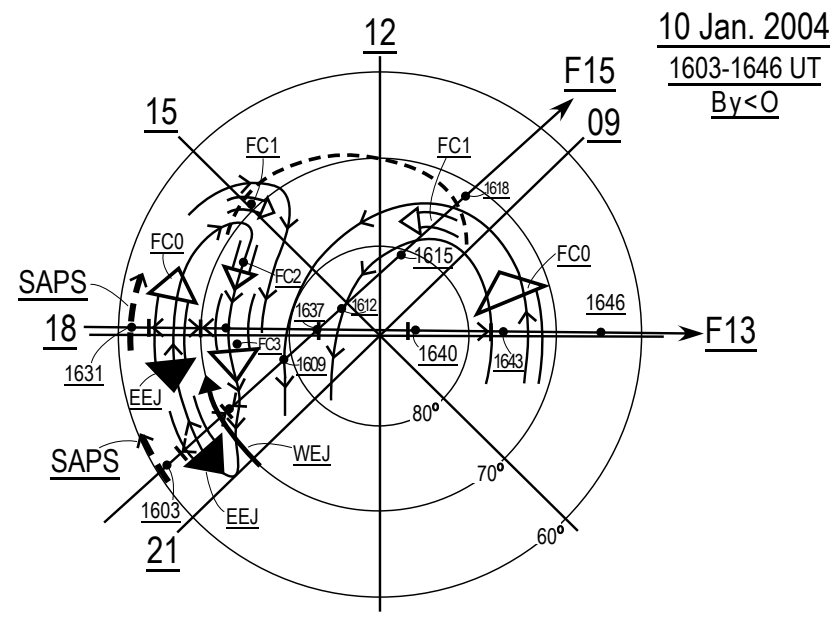

Fig. 2. Observation geometry placed in the context of global plasma convection as derived from DMSP F13 and F15 data.

pected. As a corollary, formulae for CPCP assuming linearity (e.g. Boyle et al., 1997) may be employed. An estimate of the evolution of the CPCP/day during this interval, based on the Boyle formula $(\sim 115 \mathrm{kV})$, is given in the bottom panel of Fig. 1. A propagation delay of approx. $50 \mathrm{~min}$ from ACE to Earth should be added when comparing ACE data with the low-altitude data reported below (see Sandholt et al., 2010).

\subsection{Observation geometry and global convection context}

Figure 2 is a sketch containing the main elements of the first of these conjunctions where the DMSP F13 and F15 passes are indicated. The coordinate system is MLAT vs. MLT, with dawn on the right and noon at the top. The features of polar cap convection appearing along the dusk-dawn meridian (F13 data and ground magnetograms) and the substorm activity in the dusk-premidnight sector (F15 data and ground magnetograms) we shall focus on are placed in the context of the global convection pattern as estimated on the basis of the F15 ion drift and precipitation data on the dayside.

The indicated convection geometry with emphasis on spatial structure, i.e. flow channels along the periphery of the polar cap, calls for a short comment. First of all, the two asymmetric convection cells are as expected for the prevailing ICME $B_{\mathrm{y}}$ negative conditions in our case. An outstanding feature is the traditional IMF $B_{\mathrm{y}}$-related dawn-dusk convection asymmetry (Jørgensen et al., 1972; Cowley et al., 1991; Weimer, 1995; Ruohoniemi and Greenwald, 2005).

Flow channel 1 (FC 1) represents a restricted flow channel associated with newly open field lines (LLBL, cusp, precipitation) in the prenoon and postnoon sectors. It is accompanied by poleward moving auroral forms (PMAFs; see e.g. Lockwood et al., 1989) located on either side of noon and which are separated by a sector of strongly attenuated auroral emission near noon, the "midday gap aurora" (see 
e.g. Sandholt and Farrugia, 2007). The approximate location of the open-closed field line boundary is marked by dashed curved line.

The spatial structure on the dusk side of the polar cap, which we refer to as FC 2 and FC 3, is related to the dayside and nightside sources of plasma convection, respectively. These regimes of enhanced $\left(>1 \mathrm{~km} \mathrm{~s}^{-1}\right)$ antisunward convection are accompanied by polar rain precipitation. FC 2 is a result of the persistence of open flux tubes previously opened by bursts of reconnection (flux transfer events; FTEs) along the flanks of the polar cap, as predicted by Southwood (1987). The presence of these flows has been documented by Sandholt et al. (2010). The IMF $B_{\mathrm{y}}$ dependence and the role of conductivity gradients at the polar cap boundary for the formation of these flow channels have been discussed by Sandholt and Farrugia (2009).

The presence of flow channel FC 3 on the nightside of the polar cap we attribute to the nightside source (magnetotail reconnection). The role of the conductivity gradients for the presence of flow channels in this MLT sector (beyond approx. 18:00 MLT) has been described by Wang et al. (2010) who point out their relationship to enhanced geoeffective interplanetary electric field $\left(E_{\mathrm{KL}}\right.$, Kan and Lee, 1979) and that it is mainly a winter phenomenon.

The westward and eastward-directed electrojet (WEJ and EEJ) currents in auroral oval in the Harang discontinuity region are essential elements of substorm activity in the duskpremidnight sector. An important substructure of the convection pattern appearing in association with auroral streamers (see e.g. Sergeev et al., 2004) in the substorm expansion phase is not included in this sketch.

Below we shall give a more detailed description of the observations of the ground-satellite conjunction indicated in the sketch.

1. F13 dusk-to-dawn pass across auroral oval segments and the polar cap during 16:31-16:46 UT. The following regimes are marked along the track: subauroral latitudes with subauroral polarization streams (SAPS); duskside auroral oval with flow channel FC 0 (return flow) and EEJ; polar cap with flow channel FC 3 (nightside old open field lines) at the duskside boundary; dawnside oval with FC 0.

2. F15 pass from evening to pre-noon MLTs during 16:0316:18 UT. The following regimes are marked along the track: SAPS; EEJ; WEJ; polar cap; FC 1 (flow channel associated with LLBL/cusp/mantle precipitation - poleward moving auroral forms; PMAFs).

3. Flow channels FC 1 and FC 2 are indicated on the basis of F15 data in this case and previous studies (FC 2). This flow pattern is consistent with complementary statistical studies of field-aligned current patterns inferred from Iridium data (Anderson et al., 2008) (see their

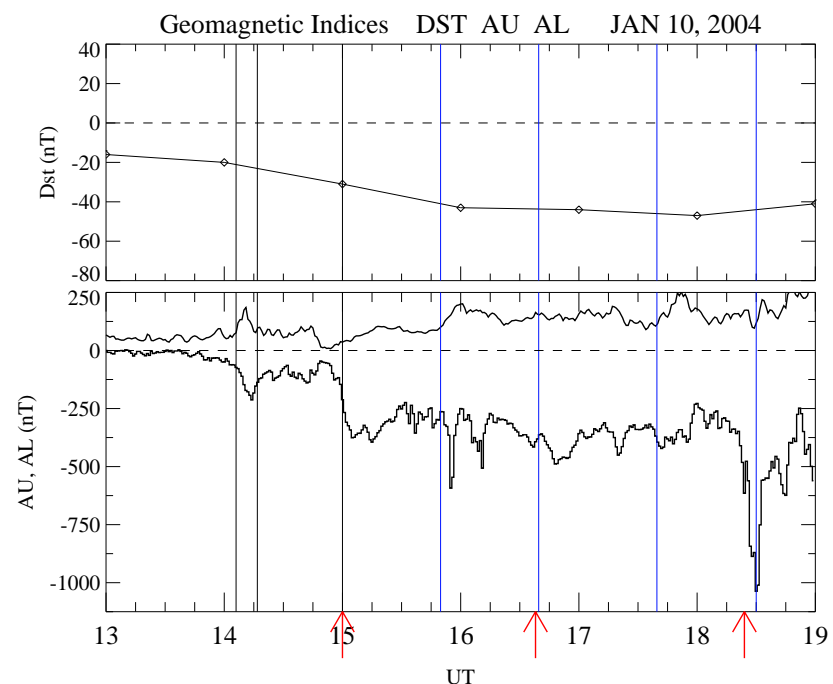

Fig. 3. Geomagnetic indices for the interval 13:00-19:00 UT: Dst (upper), AU and AL (bottom). Vertical guidelines mark (i) southward turning responses at 14:00 and 15:00 UT, (ii) substorm interval 1: 15:50-16:40 UT, and (iii) substorm interval 2: 17:4018:30 UT. Three DMSP F13 passes in the central polar cap are marked by red arrows.

Fig. 5). Flow channel FC 3 is documented by SuperDARN plot at 15:56 UT, in the second F15 conjunction at 17:47 UT, and in F13 data at 18:14 UT (see below).

In the sequel emphasis will be laid on the variability of polar cap convection in relation to substorm activity. This represents a CPCP temporal fine-structure giving rise to nontraditional polar cap flow patterns which may deviate from those expected from the actual IMF $B_{\mathrm{y}}$ conditions, i.e. the well-known IMF $B_{\mathrm{y}}$-related dawn-dusk asymmetry of polar cap convection with flow strengths in the PC increasing toward dusk (i.e. those which consider solely the dayside source). A good example on this non-traditional dawn-dusk asymmetry is the second case of F13 observations (18:1418:25 UT) we study below, showing increasing antisunward convection towards the dawn side of the $\mathrm{NH}$ polar cap during the prevailing $B_{\mathrm{y}}<0$ ICME conditions.

\subsection{Global substorm activity: AL-index on 10 January 2004}

Figure 3 shows the Dst (hour averages) and the AL and $\mathrm{AU}$ indices for the interval 13:00-19:00 UT. A moderate storm is underway during this interval. Focusing now on the ALindex (Tomita et al., 2011) for the interval 13:00-19:00 UT the following features may be noted (marked by vertical guidelines):

1. DP2 events (enhanced $E_{\mathrm{KL}}$ and associated plasma convection) at 14:00 and 15:00 UT, which are activated by southward turnings of the ICME magnetic field. DP2 is 


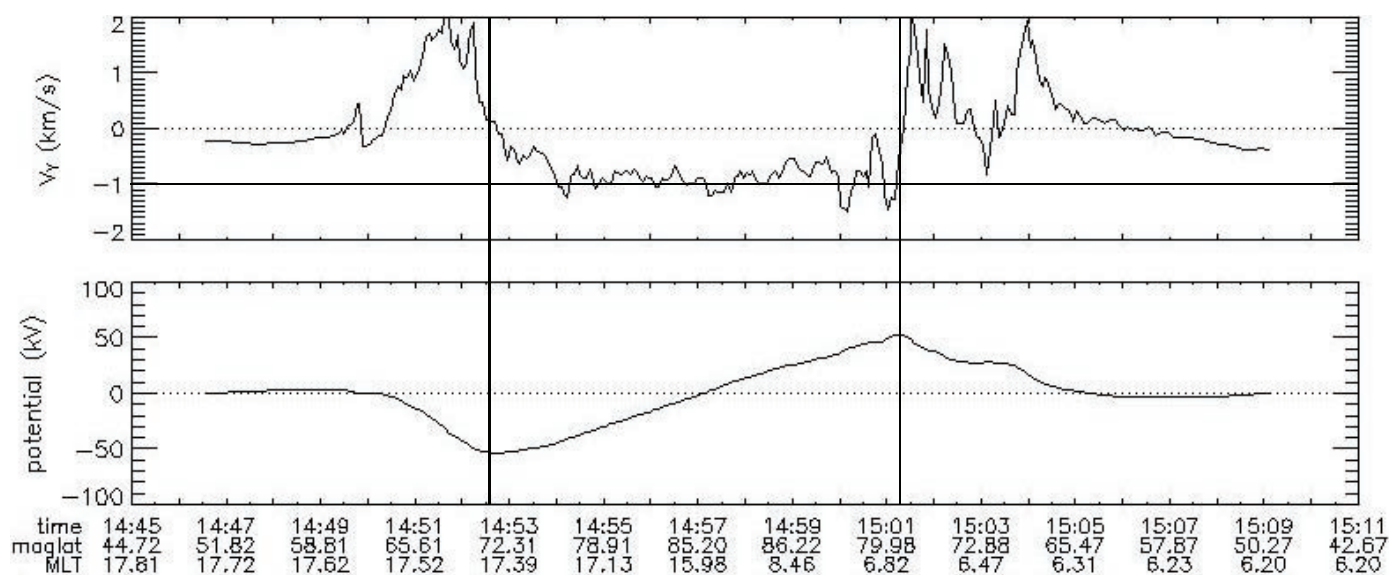

Fig. 4. DMSP F13 data showing cross-track ion drift $\left(V_{\mathrm{y}}\right)$ and electrostatic potential (bottom) for the interval 14:45-15:11 UT. Polar cap dusk- and dawn-side boundaries are marked by vertical guidelines.

defined as polar magnetic disturbances which are unrelated to substorms and controlled by the geoeffective interplanetary electric field, $E_{\mathrm{KL}}$ (Troshichev et al., 2011). So, these events are due to enhanced $E_{\mathrm{KL}}$ and associated excitation of plasma convection.

2. The two substorm intervals we study: $15: 50-16: 40$ and 17:40-18:30 UT. Blue vertical guidelines mark the two intervals of substorm activity which is clearly manifest in the local IMAGE chain magnetic deflections in the dusk-premidnight sector, as we shall show shortly. In the figure we marked by bold arrows the three DMSP F13 passes through the central polar cap (15:00, 16:38, and 17:24 UT) which we use for CPCP estimates.

\subsection{Pre-substorm conditions}

Figure 4 shows DMSP F13 cross track ion drifts $\left(V_{\mathrm{y}}\right)$ and the electrostatic potential obtained during the interval 14:45-15:11 UT. We shall focus on the interval of polar cap crossing from dusk (17.39 MLT/72.3 MLAT) to dawn (6.82 MLT/80 MLAT) during the interval 14:52:5015:01:00 UT, delimited by vertical guidelines. For this interval we derive a dawn-dusk potential drop of $107 \mathrm{kV}$. This method of deriving the CPCP is the same as that used by e.g. Hairston et al. (1998) (see their Fig. 1) Note that the pass reached high enough MLATs to sample the whole CPCP.

The interval of this CPCP measurement (14:53-15:01 UT) represents the conditions of enhanced plasma flow after the southward turning of the ICME magnetic field recorded by ACE about $1 \mathrm{~h}$ earlier, i.e. at 13:50 UT and well before the first substorm interval 15:50-16:40 UT. The excitation of FC 1-FC 2 flows (see Fig. 2) during the interval 14:5015:00 UT on this day can be seen in the IMAGE magnetometer data reported by Sandholt et al. (2010) (see their Fig. 3). On the rapid convection enhancement during the first 10
15 min after a southward turning of IMF we also refer to Greenwald et al. (1999).

\subsection{Ground-satellite conjunctions in substorm inter- val 1: 15:50-16:40 UT}

Figure 5 shows X-component magnetic deflections from IMAGE stations in Svalbard - Scandinavia - Russia. We notice the following features of the activity:

(i) a quiet interval from 15:00-15:50 UT is followed by electrojet activity lasting from 15:50 to 16:40 UT, (ii) positive X-deflection (EEJ) maximizing at stations LOZ-PEL (63-64 ${ }^{\circ}$ MLAT) near 16:00 UT, is followed by (iii) WEJ and EEJ intensifications appearing at stations BJN $\left(71^{\circ}\right.$ MLAT) and SOR $\left(67^{\circ} \mathrm{MLAT}\right)$, respectively, at 16:09 UT, and (iv) electrojet and polar cap (NAL-HOR: $75-71^{\circ}$ MLAT) magnetic deflection event at 16:37-16:40 UT, which occur at the same time when satellite F13 traversed the central polar cap (see Fig. 2).

Feature (iii) appeared just after satellite F15 crossed the oval poleward boundary ( $71^{\circ}$ MLAT) at 16:06 UT.

Figure 6 shows the observation geometry for the groundsatellite conjunction in the 18:00-21:00 MLT sector during the interval 16:00-16:10 UT. In order of increasing latitude the satellite intersected (i) SAPS, (ii) EEJ, (iii) WEJ and discrete aurora, and (iv) polar cap.

As we saw from the ground data, the satellite intersected the EEJ (16:03-16:04 UT) and WEJ (16:0516:06 UT) at the time of a local convection/electrojet enhancement, and entered the polar cap at $71^{\circ}$ MLAT, just before the larger WEJ intensification occurred at this latitude $\left(71^{\circ} \mathrm{MLAT}\right)$ at 16:08 UT. The hatched arrow centered at $76^{\circ}$ MLAT/18:00 MLT marks the polar cap flow channel detected by SuperDARN radars at 15:56 UT (data shown below). 


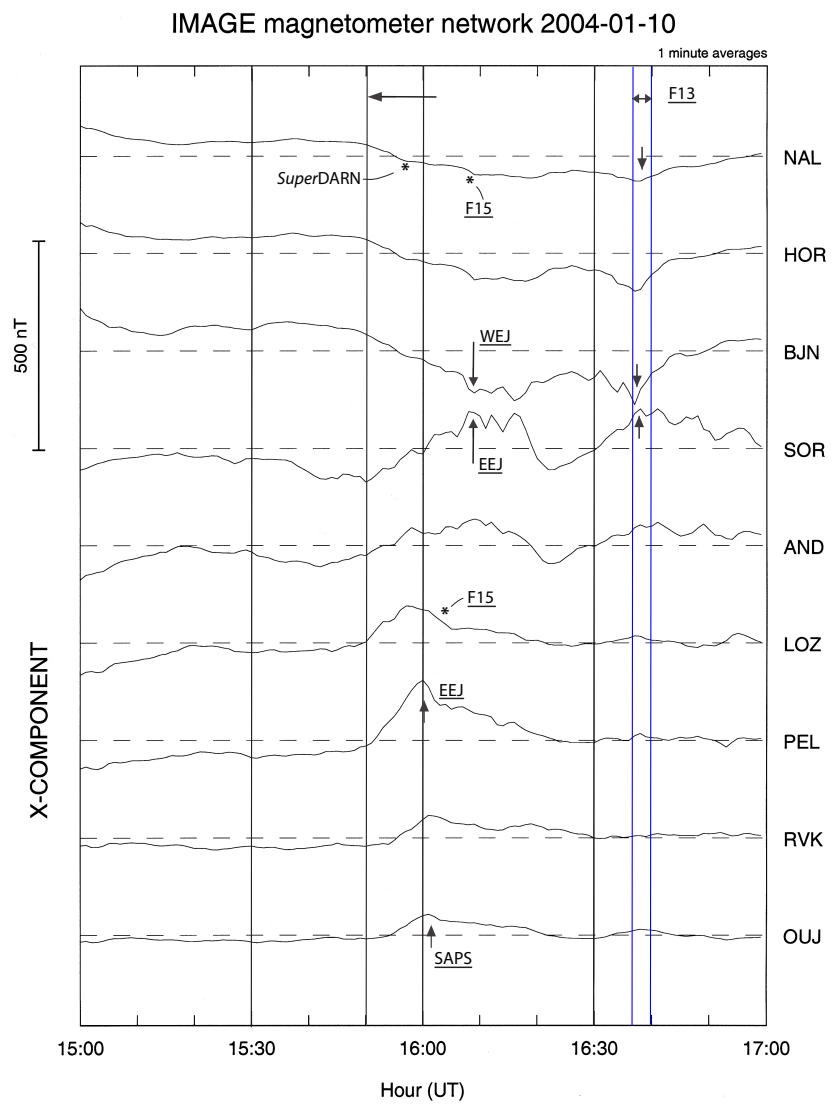

Fig. 5. The $X$-component of the geomagnetic field for the interval 15:00-17:00 UT from ground stations of the IMAGE chain in Svalbard - Scandinavia - Russia. The station acronyms are marked on the right side. Deflection maxima relating to EEJ (16:00, 16:09 and 16:38 UT) and WEJ (16:09, 16:37 UT) activities are indicated by arrows. Near perfect conjunctions of satellite F15 and ground stations LOZ (16:04 UT) and NAL (16:08 UT) have been marked by starred symbols along the respective traces. The interval of enhanced antisunward flow in the polar cap detected by F13 in the interval 16:37-16:40 UT is marked by vertical lines.

As indicated in the figure there is very good coverage of ground magnetometer stations along the 18:00 MLT meridian in this case.

Figure 7 shows the spatial plot of plasma convection (ion drift vectors and streamlines; see Ruohoniemi and Baker, 1998) in the Northern Hemisphere obtained by SuperDARN radars at 15:56 UT. We notice the presence of crescentshaped dusk-side cell as appropriate for the prevailing $B_{\mathrm{y}}<0$ conditions in the interplanetary CME and the presence of a polar cap flow channel over Svalbard, centered at 7680 MLAT/18:00 MLT.

Figure 8 shows particle precipitation, ionospheric ion drift and magnetic deflections detected by satellite DMSP F15 during the pass from pre-midnight (20:00 MLT) to pre-noon (10:00 MLT) during the interval 16:03-16:20 UT. The track is indicated in Fig. 6. We shall concentrate on the ion and

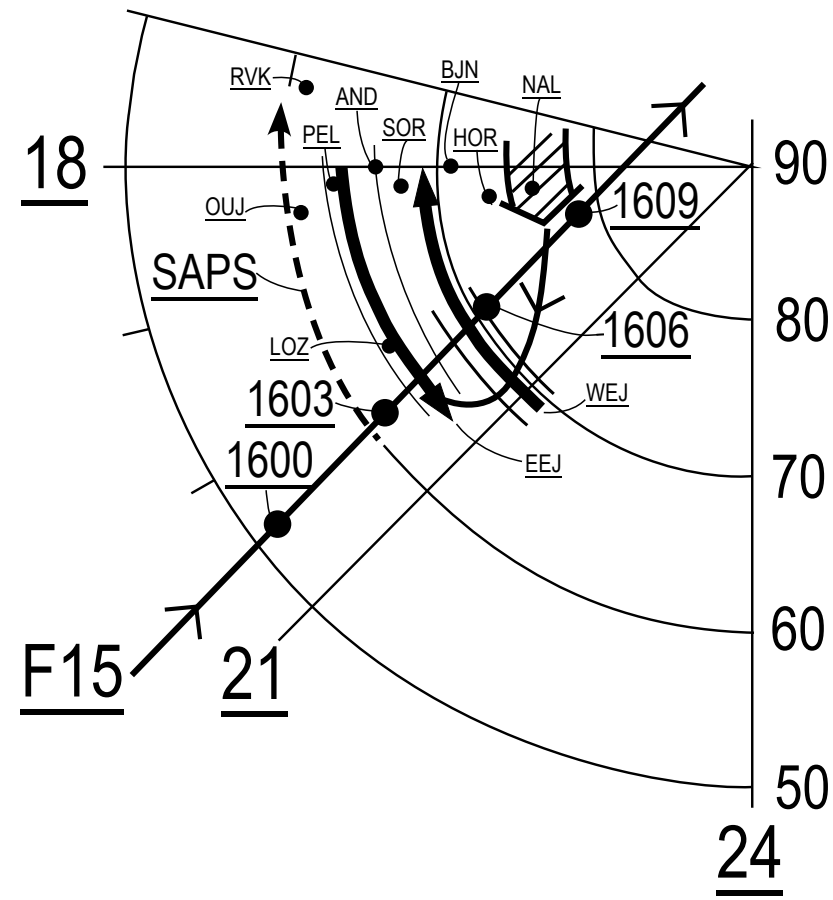

Fig. 6. Overview of ground-satellite F15 conjunction in the 18:0021:00 MLT sector during the interval 16:00-16:10 UT. The coordinate system is MLT versus MLAT. The three latitudinal regimes of (i) SAPS (westward ion drift $\left(V_{\mathrm{W}}\right)>0.5 \mathrm{~km} \mathrm{~s}^{-1}$ centered at $\sim 60^{\circ}$ MLAT), (ii) plasma sheet precipitation and the eastward electrojet (EEJ) current within $64-66^{\circ}$ MLAT, and (iii) arcs near the poleward boundary accompanied by westward electrojet (WEJ) current within $68-71^{\circ}$ MLAT have been marked along the track and in the MLT sector of the magnetometer stations. The locations of nine ground magnetometer stations in the IMAGE network (mainly along the 18:00 MLT meridian) are marked by solid dots. Solid curved lines mark the centers of the westward (WEJ) and eastward (EEJ) electrojet activities as estimated from the ground magnetograms and the satellite observations of cross-track ion drift/precipitation. The center of the westward-directed ion drift at subauroral latitudes (SAPS), as inferred from the satellite ion drift data, is marked by the westward-directed dashed curved arrow. Polar cap flow channel FC 3 (enhanced antisunward convection) above Svalbard detected by SuperDARN at $15: 56$ UT is marked by the wide, hatched arrow in the Svalbard region.

electron precipitation spectra in panels 3 and 4, the crosstrack ion drift in panel 5, and the eastward magnetic deflection (the $B_{\mathrm{Z}}$ trace) in the bottom panel. We note the following features traversed along the track: (i) westward-directed subauroral ion drift in the form of polarization streams (SAPS) and inward-directed Birkeland current within 55-61 ${ }^{\circ}$ MLAT; (ii) auroral oval precipitation and outward-directed Birkeland currents within $64-70^{\circ}$ MLAT ("most equatorward arc" at $64-66^{\circ} \mathrm{MLAT}$ ), (iii) sharp poleward boundary of aurora at $70.6^{\circ}$ MLAT, (iv) polar rain precipitation in the polar cap; and (v) enhanced noonward ion drift (flow channel FC 1) 


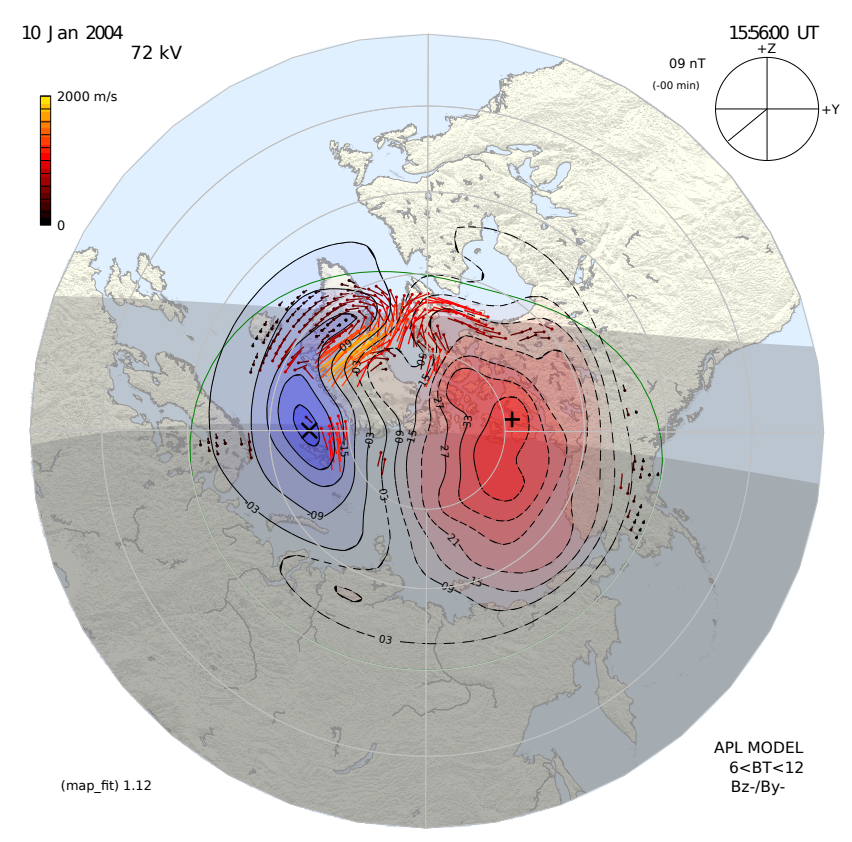

Fig. 7. SuperDARN spatial convection plot for 15:56 UT. We notice the presence of crescent-shaped dusk-side convection cell and flow channel FC 2 over Svalbard (76-80 MLAT/18:00 MLT).

within $\sim 73-78^{\circ}$ MLAT in the prenoon sector (see schematic Fig. 2) with electron precipitation structures extending to $1 \mathrm{keV}$ energy on its equatorward boundary. FACs directed in (R0/mantle current) and out (dayside R1) on the poleward and equatorward FC 1 boundaries, respectively, are marked in the figure.

The electron precipitation feature on the prenoon side (10:00 MLT), associated with flow channel FC 1, corresponds to the auroral phenomenon we refer to as PMAFs/prenoon $/ B_{\mathrm{y}}<0$, as documented in Sandholt and Farrugia (2007) (see their Figs. 7 and 8).

The satellite crossed the poleward boundary of the aurora (70.6 $\left.6^{\circ} \mathrm{MLAT} / 20: 00 \mathrm{MLT}\right)$ at 16:06 UT, just before the 16:08 UT WEJ intensification at this latitude (see the BJN magnetogram in Fig. 5).

Figure 9 shows cross-track ion drift $\left(V_{\mathrm{y}}\right)$ and the electrostatic potential curve obtained during the dusk to dawn pass of DMSP F13 during the interval 16:27-16:51 UT. The satellite track is indicated in Fig. 2.

We shall focus on the interval of polar cap traversal from the dusk-side (17.87 MLT/67.9 MLAT) to the dawnside (6.18 MLT/74.87 MLAT) polar cap boundary during the interval 16:33-16:43 UT. Enhanced antisunward convection $\left(V_{\mathrm{y}}=1.6 \mathrm{~km} \mathrm{~s}^{-1}\right)$ over a $1 \mathrm{~km} \mathrm{~s}^{-1}$ background is observed in the central polar cap during 16:37-16:40 UT. This interval is marked in Fig. 2. The CPCP value derived for this pass is $160 \mathrm{kV}$.

\subsection{Ground-satellite conjunctions in substorm inter- val 2: 17:40-18:30 UT}

Figure 10 shows eight $\mathrm{X}$-component magnetograms from the IMAGE chain of stations in Svalbard - Scandinavia - Russia for the interval 17:00-19:00 UT. The magnetograms are shown in order of decreasing latitude, from the highest (top: SOR at $67.3^{\circ} \mathrm{MLAT}$ ) to the lowest (KAR at $56^{\circ}$ MLAT) latitude. The following features are important: (i) the quiet conditions prevailing from 17:00 to 17:40 UT are followed by, (ii) sudden onset of enhanced westward electrojet (negative X-deflection) at 17:41 UT (see AND trace in the second panel), (iii) maximum of westward ( $-400 \mathrm{nT}$ at AND; $66.5^{\circ}$ ) and eastward ( $300 \mathrm{nT}$ at RVK; $62.2^{\circ}$ MLAT) electrojet deflections reached at 17:45-17:48 UT, (iv) 50-100 nT positive $\mathrm{X}$-deflections at subauroral latitudes (DOB-NUR-KAR representing the latitude range 59.3-56.4 ${ }^{\circ}$ MLAT) maximizing at 17:48-17:52 UT (see arrows at the DOB and KAR traces), (v) a second WEJ intensification ocurring at station SOR $\left(67^{\circ} \mathrm{MLAT}\right)$ at 18:05 UT was followed by streamer events (see the blue tilted lines) in the interval 18:10-18:30 UT.

Interval of enhanced polar cap convection detected by F13 in the polar cap is delimited by the blue vertical guidelines. The station locations are given in Fig. 11.

Figure 11 shows the track of satellite DMSP F15 during the interval 17:40-17:52 UT. The traversals of latitude segments of (i) enhanced $\left(>0.5 \mathrm{~km} \mathrm{~s}^{-1}\right)$ westward-directed ion drift at subauroral latitudes (SAPS within 58-62 MLAT), (ii) EEJ current within $62-64^{\circ}$ MLAT and (iii) auroral oval discrete arcs (accelerated electrons) within 64-66.5 MLAT with the westward electrojet current centered at $\sim 66^{\circ}$ MLAT have been marked.

We note that the satellite reached the latitude of auroral oval poleward boundary at 17:46 UT, i.e. just in the maximum phase of the local WEJ intensification recorded at station AND ( $66^{\circ}$ MLAT). The position of eight magnetometer stations in the IMAGE chain which are central in this study (see the X-component deflections reported above) are marked by solid dots. These stations are representative of the three latitude regimes we study, i.e. (i) KAR, NUR and DOB lie within the SAPS regime, (ii) RVK and OUJ lie within the EEJ, and (iii) SOR, AND and LOZ lie within the latitude regime of the WEJ. We note that AND and LOZ stay within the WEJ during the whole 17:42-17:50 UT event while stations RVK and OUJ are within the EEJ regime only initially (17:42-17:47). After 17:47 (OUJ) and 17:50 UT (RVK) the OUJ and RVK magnetometers are sensitive to WEJ activity. This is consistent with the equatorward expansion of the Harang discontinuity during the event.

Figure 12 shows particle precipitation, ionospheric ion drift and magnetic deflections detected by satellite DMSP F15 during the pass illustrated in Fig. 11. F15 crossed the local segment (20.5 MLT) of the oval (confined to the latitude range 64-66.5 MLAT) during the interval 07:4507:46:30 UT. Thus, F15 crossed the auroral oval poleward 


\section{F15 10 Jan 2004}

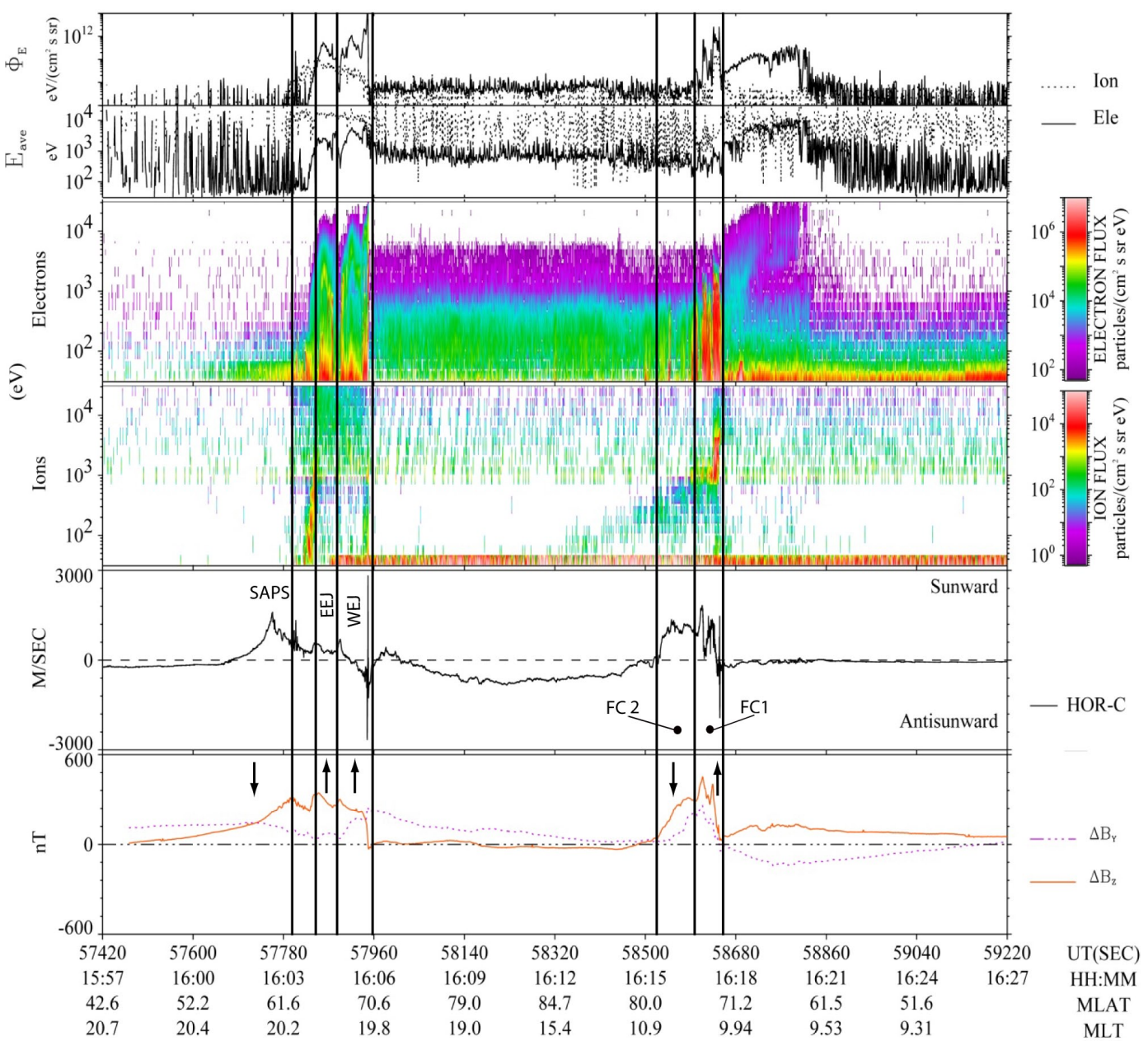

Fig. 8. DMSP F15 data obtained during the interval 15:57-16:27 UT along the track shown in Fig. 6. Panels from top to bottom shows ion (electron) precipitation energy flux, average energy, electron and ion spectrograms, cross-track ion drift, and magnetic deflection components across $\left(\Delta B_{\mathrm{Z}}\right)$ and along the track. The following latitude regimes along the 20:00 MLT meridian are marked: (i) 58-62 ${ }^{\circ}$ MLAT: enhanced subauroral ion drift/SAPS, (ii) 64-66 $6^{\circ}$ MLAT: plasma sheet precipitation (most equatorward arc) and moderate westward ion drift (the EEJ regime), and (iii) 66-70.6 $6^{\circ}$ MLAT: auroral arc at oval poleward boundary and westward electrojet (WEJ). Field-aligned current directions (in and out) are marked at the $B_{\mathrm{Z}}$-trace in the bottom panel. The vertical guidelines on the right side (prenoon sector) mark the traversal of flow channel FC 1 and electron precipitation structures extending to $1 \mathrm{keV}$ energy on its equatorward side.

boundary (centered at $66^{\circ}$ MLAT) just at the maximum of its brightening phase (17:46 UT).

We note the following features of the ion drift and magnetic field data: (i) positive $B_{\mathrm{Z}}$-gradient (inward-directed R2 FAC) and enhanced westward ion drift $V_{\mathrm{w}}\left(>0.5 \mathrm{~km} \mathrm{~s}^{-1}\right)$ in SAPS within $\sim 58-62^{\circ}$ MLAT traversed during the interval 17:43-17:44:30 UT, (ii) negative $B_{\mathrm{z}}$-gradient (outwarddirected R1 FAC) and auroral oval precipitation (boundary plasma sheet) within the MLAT range $63.5-66.5^{\circ}$ MLAT traversed during the interval 17:45-17:46:30 UT, (iii) enhanced westward ion drift (northward-directed $\boldsymbol{E}$-field) immediately equatorward of the "high-energy arc", and (iv) eastward ion drift (southward-directed $\boldsymbol{E}$-field) within the regime of dis- crete auroral precipitation ("high-energy arc"). The latter corresponds to the latitude regime of the westward electrojet (WEJ).

The latitude regimes of the westward and eastward electrojets (WEJ and EEJ) as inferred from the ground magnetic deflections are indicated in the figure. The presence of flow channel FC 3 immediately poleward of the polar cap boundary may be seen in the ion drift data.

Figure 13 shows cross-track ion drifts $\left(V_{\mathrm{y}}\right)$ and electrostatic potential curves for the interval 18:08-18:32 UT. This interval includes a dusk (18.19 MLT/67.73 ${ }^{\circ}$ MLAT) to dawn (6.34 MLT $/ 73.47^{\circ}$ MLAT) crossing of the polar cap during the interval 18:14-18:24 UT. Two features are worthy of 


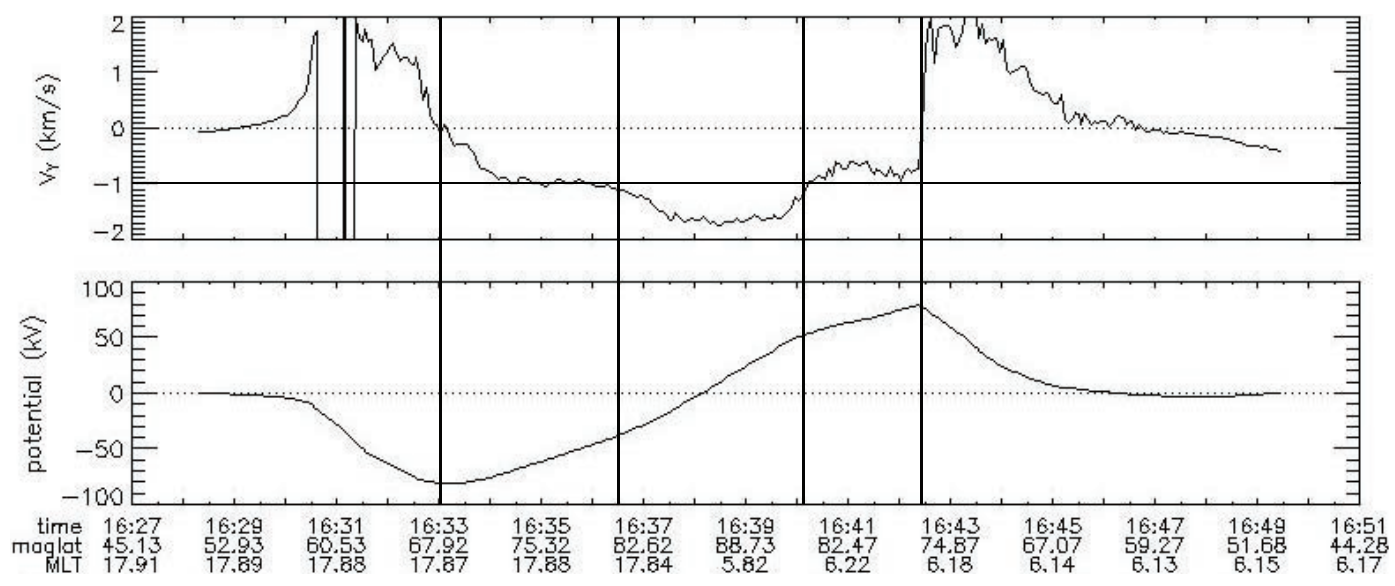

Fig. 9. DMSP F13 cross-track ion drift $\left(V_{\mathrm{y}}\right)$ and potential curves during the interval 16:27-16:51 UT. Polar cap dawn- and dusk-side boundaries and sector of enhanced antisunward flow in the central polar cap (16:37-16:40 UT) are marked by vertical guidelines. Same format as in Fig. 4. The satellite track is indicated in Fig. 2.

notice: (i) a latitudinally restricted (200 km wide) region of enhanced $\left(1 \mathrm{~km} \mathrm{~s}^{-1}\right)$ antisunward flow near the dusk side polar cap boundary (our FC 3 flow channel), bracketed by the first two vertical guidelines, and (ii) an antisunward convection increase towards the dawn side of the polar cap, with $V_{\mathrm{y}}$ exceeding $2 \mathrm{~km} \mathrm{~s}^{-1}$ on occasion on the dawn side (6.31 MLT/81.37 ${ }^{\circ}$ MLAT) of the polar cap.

The CPCP value derived from these data is $153 \mathrm{kV}$. We note that the $V_{\mathrm{y}}$-profile showing increasing antisunward convection on the dawn side of the polar cap. As we shall argue below this non-traditional dawn-dusk asymmetry is a temporal effect (rather than spatial structure) which is related to the prevailing substorm activity (see Fig. 10).

\section{Summary and discussion}

\subsection{CPCP fluctuations on 10 January 2004}

We reported cases of polar cap convection enhancements associated with two intervals of substorm activity (15:5016:40 UT and 17:40-18:30 UT) during a 4-h long interval of very steady interplanetary conditions on 10 January 2004 (15:00-19:00 UT). The steady external conditions are perfect for our purpose of determining the contribution to the polar cap potential from magnetotail reconnection.

The substantial increases in the CPCP of $\sim 50 \mathrm{kV}$ during the two substorm intervals are clearly demonstrated in Fig. 14. A stable background level of $110 \mathrm{kV}$ is observed outside the two substorm intervals.

As stated above we aim at discriminating between the dayside and nightside sources of plasma convection in this case of moderate forcing of the magnetosphere by an ICME. The dayside (magnetopause) and nightside (magnetotail) contributions to CPCP we refer to as CPCP/day and CPCP/night, respectively. The prevailing geoeffective interplanetary elec- tric field $\left(E_{\mathrm{KL}}\right)$ of $4-4.5 \mathrm{mV} \mathrm{m}^{-1}$ in our case means that we are in the upper part of the linear regime of $\mathrm{CPCP} /$ day variations in response to $E_{\mathrm{KL}}$ (see e.g. Muhlbachler et al., 2005, and Burke et al., 2007). Applying a previously derived empirical relation between IMF $B_{\mathrm{Z}}$ and $\mathrm{CPCP} /$ day $\left(\mathrm{CPCP} / B_{\mathrm{Z}}=\right.$ -20) (Yeoman et al., 2002; Milan et al., 2003) we get $120 \mathrm{kV}$ for our case $\left(B_{\mathrm{Z}}=-6 \mathrm{nT}\right)$.

Three dusk-dawn NH passes of DMSP F13 in this interval are used to derive CPCP values. The second and third F13 passes (16:37-16:40 and 18:14-18:24 UT) ocurred within the two intervals characterized by substorm electrojet intensifications ( $\mathrm{AL}=-300$ to $-400 \mathrm{nT})$. They may therefore be used to estimate $\mathrm{CPCP} /$ night.

Since the first F13 pass (14:53-15:01 UT) ocurred before substorm activity started, and just after a southward turning of the ICME field (ground magnetic signature of FC 1 is seen at 14:45-14:50 UT), this pass may be used as an estimate of the dayside (magnetopause) contribution to the CPCP in our case. From this $\mathrm{F} 13$ pass we get $\mathrm{CPCP} / \mathrm{day}=107 \mathrm{kV}$. This CPCP/day value is close to the above given estimate on the basis of the prevailing ICME $B_{\mathrm{Z}}$ value and the CPCP value derived from the Boyle formula (Boyle et al., 1997) (see below).

In the two substorm intervals we observed polar cap ion drift events in the form of enhanced $\left(>1 \mathrm{~km} \mathrm{~s}^{-1}\right)$ antisunward convection. The first convection event (16:37-16:40 UT) is short-lived ( $3 \mathrm{~min}$ ), occurring when F13 was in central polar cap (marked along the F13 track in Fig. 9), while the second event (18:14-18:24 UT) lasted longer than the $10 \mathrm{~min}$ period of the F13 polar cap transit. In the latter case the cross-track ion drift (antisunward flow) increased continuously during the pass from the dusk to the dawn side of the polar cap when a substorm was in progress. The result is a dawn-dusk asymmetric convection profile in the Northern Hemisphere which is totally unexpected, being in the opposite sense to 


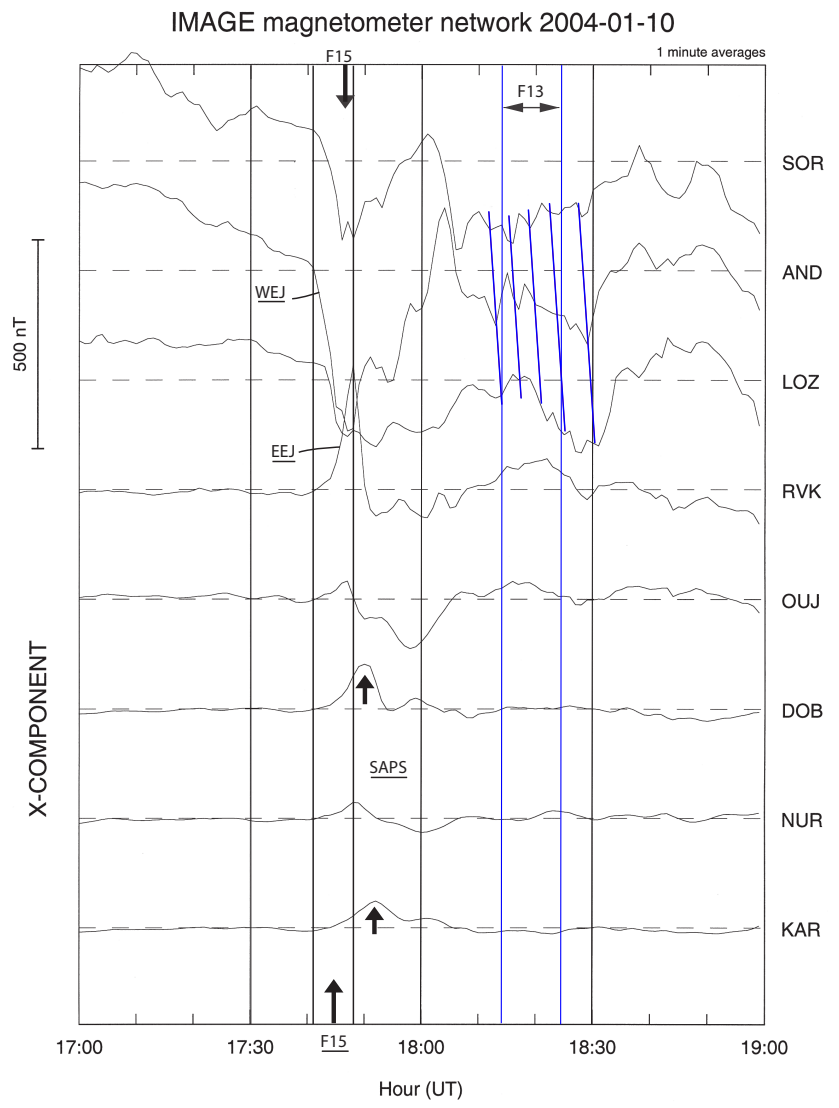

Fig. 10. X-component magnetograms from eight selected stations in the IMAGE chain of stations in Svalbard - Scandinavia - Russia for the interval 17:00-19:00 UT. The station acronyms are marked on the right side. The onset of electrojet activity (WEJ at station AND) at 17:41 UT and the maximum phase of the westward $\left(-400 \mathrm{nT}\right.$ at AND; $66.4^{\circ}$ MLAT) and eastward (300 nT at RVK; $62^{\circ}$ MLAT) electrojet deflections at 17:48 UT are marked by vertical guidelines. A series of auroral streamers in the interval 18:1018:30 UT are shown by the blue tilted lines. Interval of F13 duskdawn crossing of the polar cap is marked by blue vertical lines.

that expected in view of the prevailing $B_{\mathrm{y}}<0$ ICME conditions. This is an interval of substorm electrojet activity and the presence of auroral streamers (see e.g. Sandholt et al., 2002, and Sergeev et al., 2004) emanating from the polar cap boundary (see Fig. 10).

Both these polar cap traversals are characterized by a convection structure subject to temporal variability, as can be derived from the continuous monitoring of the associated ground magnetic deflections in the polar cap and in the nightside oval with its auroral electrojet activity.

Various techniques may be applied to distinguish between the dayside and nightside sources of the CPCP as estimated from the F13 data in our cases.

If we assume that $\mathrm{CPCP} /$ day is approximately constant in our case, as indicated by the DMSP observations in Fig. 14, and the constant $E_{\mathrm{KL}}$, we may use the first po-

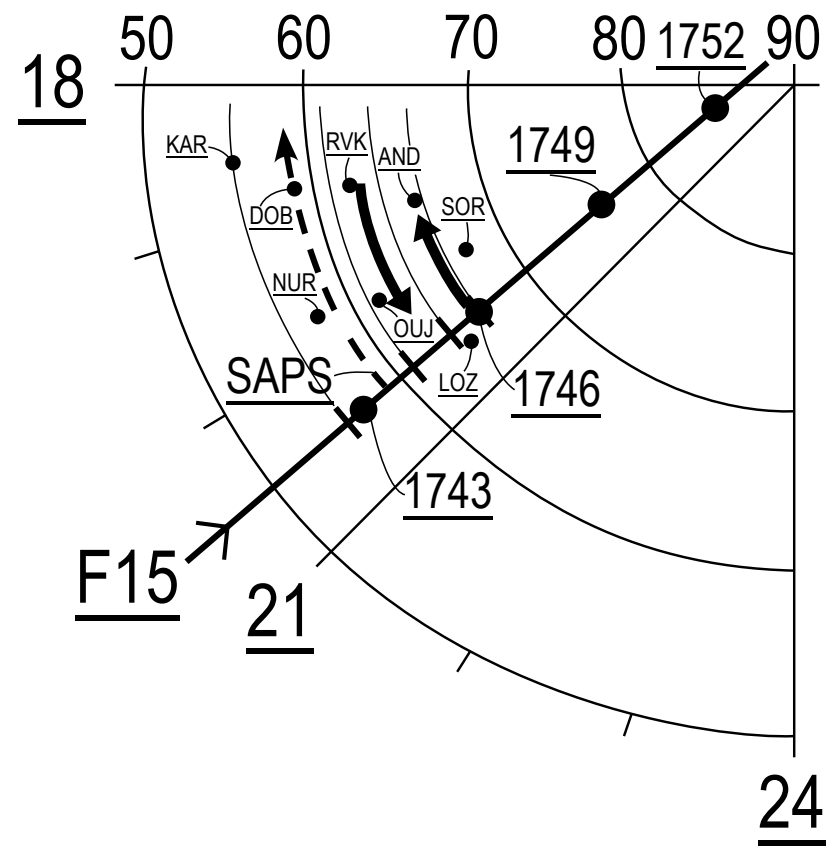

Fig. 11. Observation geometry of ground-satellite conjunction in the 19:00-21:00 MLT sector with track of satellite DMSP F15 marked during the interval 17:43-17:52 UT. The three latitudinal regimes of (i) subauroral polarization streams (SAPS; westward ion drift $\left(V_{\mathrm{W}}\right)>0.5 \mathrm{~km} \mathrm{~s}^{-1}$ within $\sim 58-62^{\circ} \mathrm{MLAT}$ ), (ii) central plasma sheet precipitation and the eastward electrojet (EEJ) current within $62-64^{\circ}$ MLAT, and (iii) auroral oval (AO) arcs within 64-66.5 MLAT and the westward electrojet (WEJ) centered at $\sim 66^{\circ}$ MLAT have been marked along the track and in the MLT sector of the magnetometer stations. The coordinate system is MLT versus MLAT. The locations of eight stations of ground magnetometers in the IMAGE chain are marked by solid dots. Solid curved lines mark the centers of the westward (WEJ) and eastward (EEJ) electrojet activities as estimated from the ground magnetograms and the satellite observations of cross-track ion drift. The center of the westward-directed ion drift at subauroral latitudes (SAPS) which is marked by the dashed curved arrow is inferred from the satellite data.

lar cap pass (14:53-15:01 UT) as an estimate of CPCP/day $(107 \mathrm{kV})$. This is also consistent with the CPCP value derived from the Boyle formula (Boyle et al., 1997) in our case: $112.8 \pm 3.7 \mathrm{kV}$ (see Fig. 1).

The two values of the total CPCP we derived for the intervals $16: 33-16: 43$ and 18:14-18:24 UT are 160 and $153 \mathrm{kV}$, respectively. If we subtract the $\mathrm{CPCP} /$ day value we got from the first $\mathrm{F} 13$ pass $(107 \mathrm{kV})$, under quiet substorm conditions, we find that $\mathrm{CPCP} /$ night is 53 and $46 \mathrm{kV}$ in these two cases. From this estimate we find that the actual substorm activities caused a $50 \%$ increase in the total CPCP we measure.

A more direct method to extract $\mathrm{CPCP} /$ day from the second pass, which includes the 16:37-16:40 UT short-lived event, may be to use the potential curves in Fig. 9 to extrapolate the pre-event drift velocity $\left(V_{\mathrm{y}}=1 \mathrm{~km} \mathrm{~s}^{-1}\right)$ across 


\section{F15 10 Jan 2004}

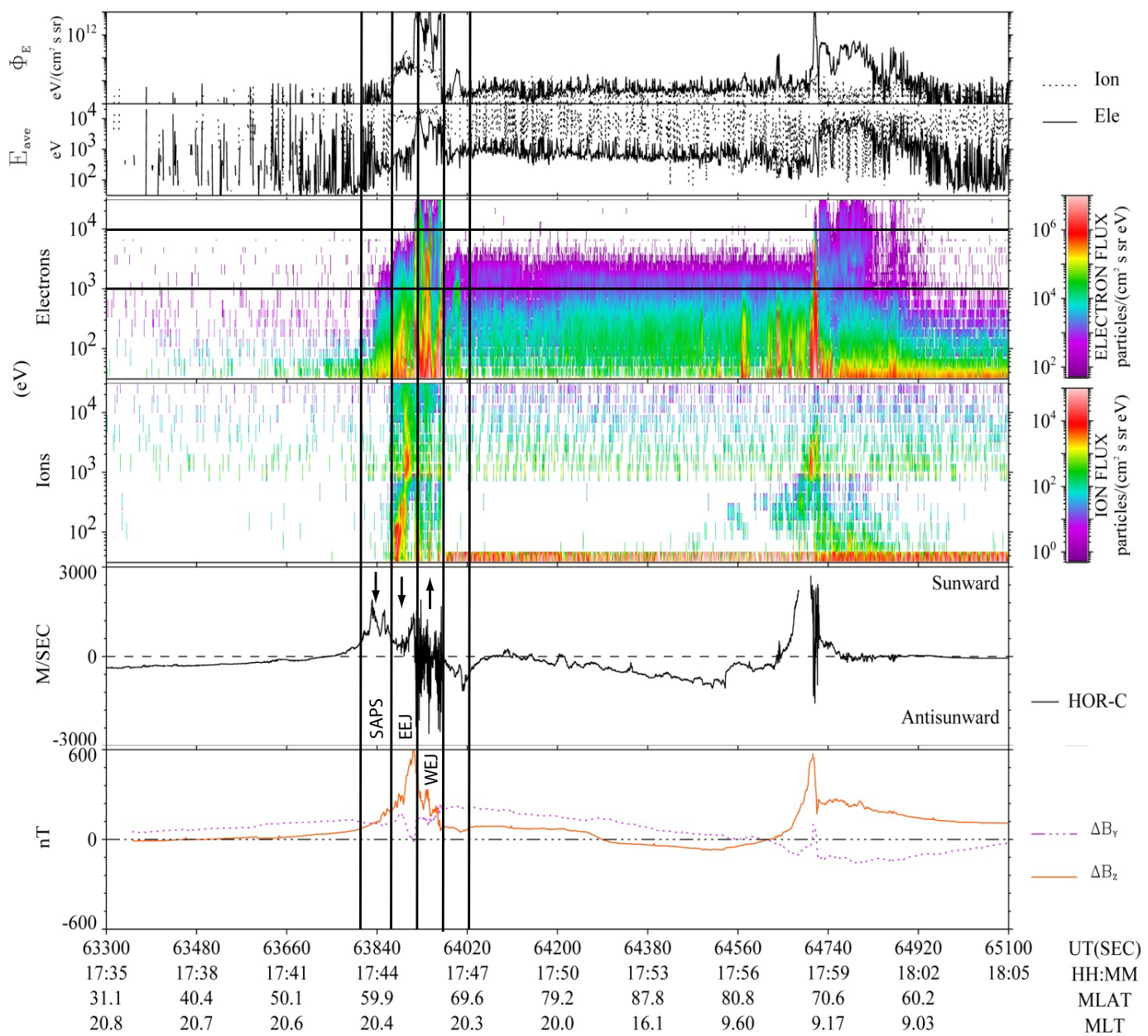

Fig. 12. DMSP F15 data obtained during the interval 17:35-18:05 UT. Same format as in Fig. 8. Latitude regimes corresponding to subauroral polarization stream (SAPS), and the eastward and westward electrojets (EEJ and WEJ) have been delimited by vertical guidelines. Fieldaligned current directions (R2 in: positive $B_{\mathrm{Z}}$ gradient; and R1 out: negative $B_{\mathrm{Z}}$ gradient) are marked in the ion drift panel.

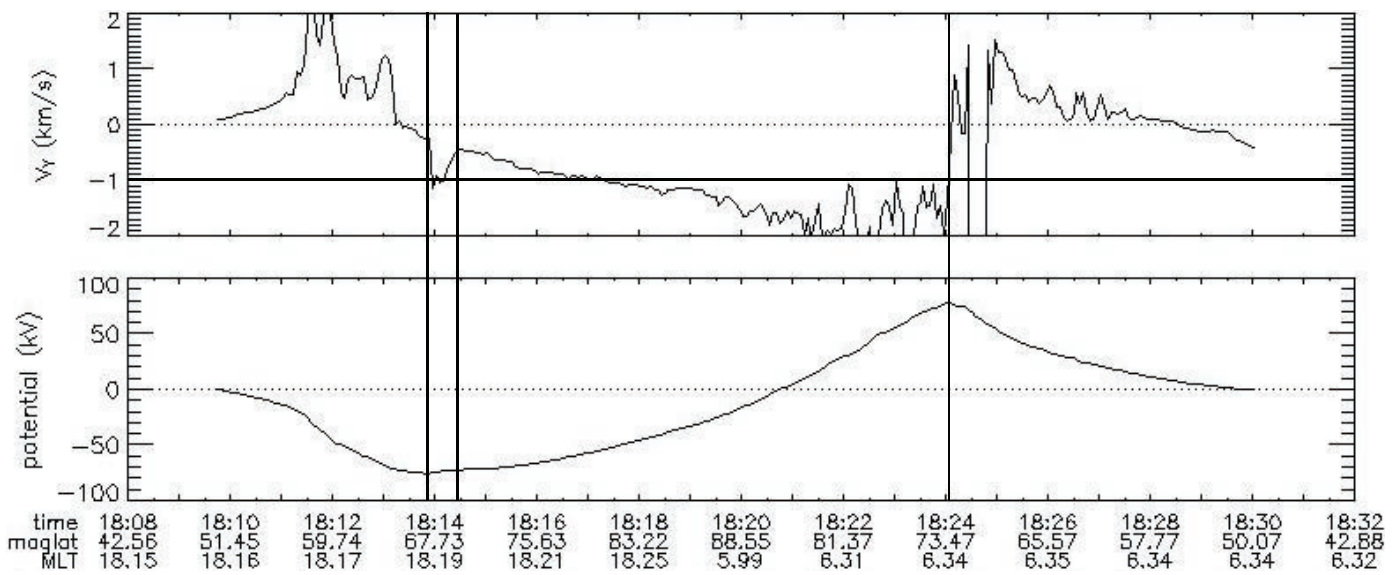

Fig. 13. DMSP F13 cross-track ion drift $\left(V_{\mathrm{y}}\right)$ and electrostatic potential curves for the interval 18:08-18:32 UT. Flow channel FC 3 at the dusk side polar cap boundary is marked by the two first guidelines. The third guideline marks the polar cap boundary on the dawn side. 


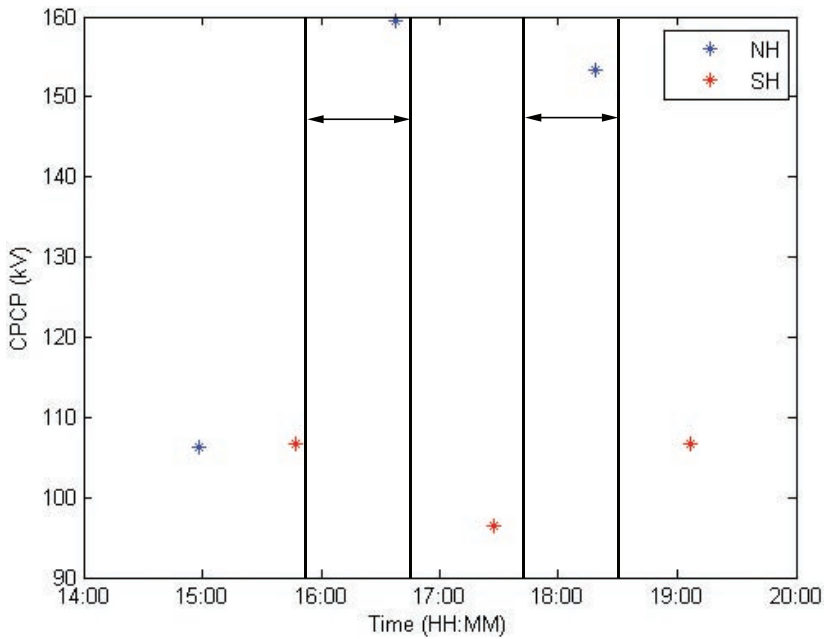

Fig. 14. CPCP estimates derived from F13 cross-track ion drift observations across the polar cap in both hemispheres. Two intervals of enhanced substorm activity are marked by vertical guidelines.

the whole polar cap to obtain $\mathrm{CPCP} /$ day. This gives $\mathrm{CPCP}$ (pre-event) $=120 \mathrm{kV}$, which is slightly higher that the result of the first method. The corresponding $\mathrm{CPCP} / B_{\mathrm{Z}}$ ratio is 20 , which is exactly the same value as derived by Yeoman et al. (2002). If this method is used, the consequence is that $\mathrm{CPCP} / \mathrm{night}=40 \mathrm{kV}$ (33\% increase) in this case.

A questionable point in the last approach is that the pre-event value of CPCP may contain a contribution from $\mathrm{CPCP} /$ night since the pre-event conditions (15:50-16:37 UT) are not void of substorm activity which prevails during the interval 15:50-16:40 UT (see Fig. 5).

\subsection{On the relative strengths of $\mathrm{CPCP} / \mathrm{day}$ and CPCP/night}

Some studies of the relative contributions of $\mathrm{CPCP} /$ day and $\mathrm{CPCP} /$ night to the total $\mathrm{CPCP}$ $(\mathrm{CPCP}=\mathrm{CPCP} /$ day $+\mathrm{CPCP} /$ night $)$, as measured along the dawn-dusk meridian, have been reported over the last 10 years. Some of these results are summarized below. Grocott et al. (2002) found $100 \%$ CPCP increase associated with an isolated substorm. The CPCP increase occurred during a $15 \mathrm{~min}$ interval of the expansion phase, and then decayed to the pre-onset level over $\sim 10$ min during recovery. A similar effect is documented in Provan et al. (2004).

Lockwood et al. (2009) found that CPCP/night makes the larger contribution during the expansion and recovery phases but not in the growth phase when CPCP/day dominates. In his cases the substorm expansion phase typically gave rise to $100 \%$ CPCP increase.

In the statistical study of Kullen et al. (2010) the average substorm response (CPCP/night) represents approx. 40-50\% instantaneous increase of the CPCP at substorm onset. A smaller substorm effect is obtained by Gordeev et al. (2011).
In their MHD simulations, substorm onset gives rise to a CPCP increase of approx. $25 \%$.

Comparing with these previous calculations our estimates of approx. 50\% CPCP increase associated with the substorm activity is comparable to the results of Kullen et al. (2010). Thus, we find that the $\mathrm{CPCP} /$ night contribution to $\mathrm{CPCP} /$ total during substorms is significantly higher than the estimates of Gordeev et al. (2011), but less than the values obtained by Lockwood et al. (2009).

\subsection{Non-traditional dawn-dusk convection asymmetry}

The non-traditional dawn-dusk convection asymmetry we find during intervals of substorm activity (see Fig. 13) illustrates that substorms significantly disturb the polar cap convection pattern imposed by the IMF $B_{\mathrm{y}}$-related magnetopause reconnection geometry (see e.g. Moore et al., 2002) and confirms that magnetopsheric convection is driven by two independent sources. We demonstrate that a substormrelated distortion of the convection pattern is strongly present in our satellite measurements along the dawn-dusk meridian during the interval 18:14-18:24 UT. In this case the dawndusk convection asymmetry (enhanced antisunward convection on the dawn side of the polar cap) is opposite to the traditonal $B_{\mathrm{y}}$ negative pattern indicated in Fig. 2. But this is in our view due to a temporal evolution of polar cap convection occurring during the DMSP F13 traversal of the polar cap when the substorm is in progress (see Figs. 13 and 3).

Our result on this point is consistent with the previously published radar observations by Grocott et al. (2010). They found "a lack of IMF $B_{\mathrm{y}}$-control in the nightside auroral zone. On the dayside each pattern exhibits the expected $B_{y}$ asymmetry, yet on the nightside the asymmetry is exactly the opposite to that associated with IMF $B_{\mathrm{y}}$ in the absence of substorms."

\subsection{Spatial-temporal convection structure: flow chan- nels at the polar cap boundary}

The temporal nature of polar cap antisunward flow events is well illustrated by the F13 event at 16:37-16:40 UT (Fig. 9). The correlation with the temporal evolution of the auroral electrojet is demonstrated in Fig. 5.

On the other hand, spatial structure, in the form of enhanced flow near the dawn/dusk side boundaries of the polar cap, is also seen in our data set: (i) dusk-side flow channel in substorm interval 1 (15:55 UT SuperDARN plot in Fig. 7), (ii) dusk-side flow channel in substorm interval 2 (F13 ion drift data at 18:14 UT; Fig. 13), and (iii) dawnside flow channel in substorm interval 2 (F13 ion drift data during 18:35-18:40 UT when the WEJ intensification was in progress).

Previous studies of flow channels at the nightside polar cap boundary (Wang et al., 2010) reveal relationships with (i) conductivity gradient at the polar cap boundary, (ii) the 
degree of solar wind forcing (high $E_{\mathrm{KL}}$ ), and (iii) solar ionization state ("winter phenomenon").

All these three factors are favourable for flow channel formation in our case. In addition we would like to add one parameter which seems to be favorable too: substorm activity.

Finally, we would like to point out one difference between flow channels FC 2 and FC 3, in addition to the different momentum source in the solar wind-magnetosphere-ionosphere system. The relationship with the FAC configuration may be different. FC 2 is related to ionospheric Pedersen current closure of FACs located poleward of the R1-R2 system, generated in the magnetospheric boundary layers (coupled HBL/LLBL dynamo system) (Sandholt and Farrugia, 2009). In the model of Wang et al. (2010) the FC 3 channel is located immediately poleward of the nightside oval FACs (see Wang et al., 2010, their Figs. 1 and 8). This is also confirmed by our DMSP observations reported in Fig. 12. The F15 ion drift data shows an FC 3 flow channel immediately poleward of the polar cap boundary at 17:46-17:48 UT (centered at $68^{\circ}$ MLAT/20 MLT), when the WEJ maximizes at stations AND and SOR $\left(66-67^{\circ} \mathrm{MLAT}\right)$. On the latitude profiles of conductivity and E-field (ion drift) at the polar cap boundary during substorms we also refer to Kamide and Kokubun (1996) (see their Fig. 4).

Acknowledgements. Access to the DMSP data base (https://swx. plh.af.mil) was kindly provided by Air Force Geophysics Research Laboratory, Hanscom, Mass through Gordon Wilson. Ground magnetograms from the Svalbard IMAGE chain of ground stations were obtained from http://www.geo.fmi.fi/image. We thank Ari Viljanen and Truls Lynne Hansen for IMAGE chain magnetograms and W. Denig for providing high-quality DMSP F15 data used in Figs. 8 and 12. We thank M. Ruohoniemi and the SuperDARN team for the convection plots. Work at University of Oslo is supported by the Norwegian Research Council (NFR). Work at UNH is supported by NASA grant NNX10AQ29G.

Topical Editor I. A. Daglis thanks W. Denig and another anonymous referee for their help in evaluating this paper.

\section{References}

Anderson, B. J., Korth, H., Waters, C. L., Green, D. L., and Stauning, P.: Statistical Birkeland current distributions from magnetic field observations by the Iridium constellation, Ann. Geophys., 26, 671-687, doi:10.5194/angeo-26-671-2008, 2008.

Boyle, C. B., Reiff, P. H., and Hairston, M. R.: Empirical polar cap potentials, J. Geophys. Res., 102, 111-125, 1997.

Burke, W. J., Gentile, L. C., and Huang, C. Y.: Penetration electric fields driving main phase Dst, J. Geophys. Res., 112, A07206, doi:10.1029/2006JA012137, 2007.

Cowley, S. W. H.: Solar wind control of magnetospheric convection, in: Achievements of the International Magnetospheric Study, no. 217 in ESA SP, pp. 483-494, 1984.

Cowley, S. W. H. and Lockwood, M.: Excitation and decay of solar wind-driven flows in the magnetosphere-ionosphere system, Ann. Geophys., 10, 103-115, 1992.
Cowley, S. W. H., Morelli, J. P., and Lockwood, M.: Dependence of convective flows and particle precipitation in the high-latitude dayside ionosphere on the $\mathrm{X}$ and $\mathrm{Y}$ components of the interplanetary magnetic field, J. Geophys. Res., 96, 5557-5564, 1991.

Gordeev, E. I., Sergeev, V., Pulkkinen, T. I., and Palmroth, M.: Contribution of magnetotail reconnection to the cross-polar cap electric potential drop, J. Geophys. Res., 116, A08219, doi:10.1029/2011JA016609, 2011.

Greenwald, R. A., Ruohoniemi, J. M., Baker, K., Bristow, W. A., Sofko, G. J., Villain, J. P., Lester, M., and Slavin, J.: Convective response to a transient increase in dayside reconnection, $\mathrm{J}$. Geophys. Res., 104, 10007-10015, 1999.

Grocott, A., Cowley, S. W. H., Sigwarth, J. B., Watermann, J. F., and Yeoman, T. K.: Excitation of twin-vortex flow in the nightside high-latitude ionosphere during an isolated substorm, Ann. Geophys., 20, 1577-1601, doi:10.5194/angeo-20-1577-2002, 2002.

Grocott, A., Milan, S. E., and Yeoman, T. K.: Superposed epoch analysis of the ionospheric convection evolution during substorms: IMF $B_{\mathrm{y}}$ dependence, J. Geophys. Res., 115, A00I04, doi:10.1029/2010JA015663, 2010.

Hairston, M. R., Heelis, R. A., and Rich, F. J.: Analysis of the ionospheric cross polar cap potential using DMSP data during the National Space Weather Program study period, J. Geophys. Res., 103, 26337-26347, 1998.

Jørgensen, T. S., Friis-Christensen, E., and Wilhjelm, J.: Interplanetary magnetic field direction and high-latitude ionospheric currents, J. Geophys. Res., 77, 1976-1977, 1972.

Kamide, Y. and Kokubun, S.: Two-component auroral electrojet: importance for substorm studies, J. Geophys. Res., 101, doi:10.1029/96JA00142, 1996.

Kan, J. R. and Lee, L. C.: Energy coupling function and solar windmagnetosphere dynamo, Geophys. Res. Lett., 6, 577-580, 1979.

Kullen, A., Karlsson, T., Cumnock, J. A., and Sundberg, T.: Occurrence and properties of substorms associated with pseudobreakups, J. Geophys. Res., 115, A12310, doi:10.1029/2010JA015866, 2010.

Lockwood, M. and Cowley, S. W. H.: Ionospheric convection and the convection cycle, in: SUBSORMS 1, no. 335 in ESA - SP, pp. 99-109, 1992.

Lockwood, M., Sandholt, P. E., and Cowley, S. W. H.: Dayside auroral activity and magnetic flux transfer from the solar wind, Geophys. Res. Lett., 16, 33-36, 1989.

Lockwood, M., Hairston, M., Finch, I., and Roillard, A.: Transpolar voltage and polar cap flux during the substorm cycle, J. Geophys. Res., 114, A0120, doi:10.1029/2008JA013697, 2009.

Lopez, R. E.: Solar cycle invariance in solar wind proton temperature relationships, J. Geophys. Res., 92, 11189-11194, 1987.

McComas, D. J., Bame, S. J., Barker, P., Feldman, W. C., Phillips, J. L., Riley, P., and Griffee, J. W.: Solar wind electron proton alpha monitor (SWEPAM) for the Advanced Compostion Explorer, Space Sci. Rev., 86, 563-612, 1998.

Milan, S. E., Lester, M., Cowley, S. W. H., Oksavik, K., Brittnacher, M., Greenwald, R. A., Sofko, G., and Villain, J.-P.: Variations in the polar cap area during two substorm cycles, Ann. Geophys., 21, 1121-1140, doi:10.5194/angeo-21-1121-2003, 2003.

Moore, T. E., Fok, M.-C., and Chandler, M. O.: The dayside reconnection X line, J. Geophys. Res., 107, 1332, doi:10.1029/2002JA009381, 2002.

Muhlbachler, S., Farrugia, C. J., Raeder, J., Biernat, H. K., and Tor- 
bert, R.: A statistical investigation of dayside magnetosphere erosion showing saturation of response, J. Geophys. Res., 110, A11207, doi:10.1029/2005JA011177, 2005.

Provan, G., Lester, M., Mende, S. B., and Milan, S. E.: Statistical study of high-latitude plasma flow during magnetospheric substorms, Ann. Geophys., 22, 3607-3624, doi:10.5194/angeo-223607-2004, 2004.

Provan, G., Lester, M., Grocott, A., and Cowley, S. W. H.: Pulsed flows observed during an interval of prolonged northward IMF, Ann. Geophys., 23, 1207-1225, doi:10.5194/angeo-23-12072005, 2005.

Ruohoniemi, J. M. and Baker, K. B.: Large-scale imaging of highlatitude convection with Super Dual Auroral Radar Network HF radar observations, J. Geophys. Res., 103, 20797-20811, 1998.

Ruohoniemi, J. M. and Greenwald, R. A.: Dependencies of high-latitude plasma convection: Consideration of interplanetary magnetic field, season, and universal time factors in statistical patterns, J. Geophys. Res., 110, A09204, doi:10.1029/2004JA010815, 2005.

Sandholt, P. E. and Farrugia, C. J.: Poleward moving auroral forms (PMAFs) revisited: responses of aurorae, plasma convection and Birkeland currents in the pre- and postnoon sectors under positive and negative IMF $B_{\mathrm{y}}$ conditions, Ann. Geophys., 25, 16291652, doi:10.5194/angeo-25-1629-2007, 2007.

Sandholt, P. E. and Farrugia, C. J.: Plasma flow channels at the dawn/dusk polar cap boundaries: momentum transfer on old open field lines and the roles of IMF $B_{\mathrm{y}}$ and conductivity gradients, Ann. Geophys., 27, 1527-1554, doi:10.5194/angeo-271527-2009, 2009.

Sandholt, P. E., Farrugia, C. J., Lester, M., Cowley, S. W. H., Milan, S., Denig, W. F., Lybekk, B., Trondsen, E., and Vorobjev, V.: Multistage substorm expansion: Auroral dynamics in relation to plasma sheet particle injection, precipitation, and plasma convection, J. Geophys. Res., 107, 1342, doi:10.1029/2001JA900116, 2002.

Sandholt, P. E., Andalsvik, Y., and Farrugia, C. J.: Polar cap flow channel events: spontaneous and driven responses, Ann. Geophys., 28, 2015-2025, doi:10.5194/angeo-28-2015-2010, 2010.
Sergeev, V. A., Liou, K., Newell, P. T., Ohtani, S.-I., Hairston, M. R., and Rich, F.: Auroral streamers: characteristics of associated precipitation, convection and field-aligned currents, Ann. Geophys., 22, 537-548, doi:10.5194/angeo-22-537-2004, 2004.

Shepherd, S. G., Greenwald, R. A., and Ruohoniemi, J. M.: Cross polar cap potentials measured with Super Dual Auroral Radar Network during quasi-steady solar wind and interplanetary magnetic field conditions, J. Geophys. Res., 107, 1094, doi:10.1029/2001JA000152, 2002.

Siscoe, G. L. and Huang, T. S.: Polar cap inflation and deflation, J. Geophys. Res., 90, 543-547, 1985.

Smith, C. W., L'Heureux, J., Ness, N. F., Acuna, M. H., Burlaga, L. F., and Scheifele, J.: The ACE magnetic fields experiment, Space Sci. Rev., 86, 613-632, 1998.

Southwood, D. J.: The ionospheric signature of flux transfer events, J. Geophys. Res., 92, 3207-3213, 1987.

Tomita, S., Nosé, M., Iyemori, T., Toh, H., Takeda, M., Matzka, J., Bjornsson, G., Saemundsson, T., Janzhura, A., Troshichev, O., and Schwarz, G.: Magnetic local time dependence of geomagnetic disturbances contributing to the AU and AL indices, Ann. Geophys., 29, 673-678, doi:10.5194/angeo-29-673-2011, 2011.

Troshichev, O. A., Podorozhkina, N. A., and Janzhura, A. S.: Invariability of relationship between the polar cap magnetic activity and geoeffective interplanetary electric field, Ann. Geophys., 29, 1479-1489, doi:10.5194/angeo-29-1479-2011, 2011.

Wang, H., Lühr, H., and Ridley, A. J.: Plasma convection jets near the poleward boundary of the nightside auroral oval and their relation to Pedersen conductivity gradients, Ann. Geophys., 28, 969-976, doi:10.5194/angeo-28-969-2010, 2010.

Weimer, D. R.: Models of high-latitude electric potentials derived with a least error fit of spherical harmonic coefficients, J. Geophys. Res., 100, 19595-19608, 1995.

Yeoman, T. K., Hanlon, P. G., and McWilliams, K. A.: Letter to the Editor: A statistical study of the location and motion of the HF radar cusp, Ann. Geophys., 20, 275-280, doi:10.5194/angeo-20275-2002, 2002. 